\title{
Limited protection of rabbits against infection with Treponema pallidum by immune rabbit sera
}

\author{
S. GRAVES AND J. ALDEN \\ From the Department of Microbiology, Monash University Medical School, Alfred Hospital, Prahran, \\ Australia
}

SUMMARY After intradermal infection of rabbits with $3 \times 10^{6}$ Treponema pallidum (Melbourne 1 strain) samples of serum were taken at one, two, three, four, and six months after infection. Normal rabbits were passively immunised with these sera, challenged with intradermal doses $\left(10^{4}\right.$, $\left.10^{3}, 10^{2}, 10\right)$ of $T$. pallidum, and the latent periods of infection, lesion diameters, and the number of inoculation sites developing into lesions were observed. The sera taken at three, four, and six months reduced the number of intradermal inoculation sites that developed into syphilitic lesions after challenge with $10 \mathrm{~T}$. pallidum. These same three sera also increased the latent period of infection after challenge with $10^{4} \mathrm{~T}$. pallidum. The transfer of $50 \mathrm{ml}$ of immune serum per rabbit over a nine-day period before challenge had very little effect on the course of the challenge infection. Only a low level of immunity in rabbits to this strain of $T$. pallidum appears to be mediated by immune serum but this small degree of protection did increase with time after infection. Enhanced growth of $T$. pallidum in the serum-recipient rabbits did not occur, thus suggesting that none of the sera was immunosuppressive.

\section{Introduction}

It is generally recognised that immunity to Treponema pallidum in both humans and rabbits develops slowly (Turner and Hollander, 1957). Humans with untreated syphilis remain susceptible to reinfection until such time as their initial infection becomes latent (Magnuson et al., 1956). Persons with primary and secondary lesions remain susceptible to exogenous $T$. pallidum. In rabbits the disease must progress for approximately three months before complete resistance to challenge is established (Turner and Hollander, 1957). The reasons for this slow onset of immunity are not known but may be due to the recently recognised immunosuppression that occurs early in syphilis (Pavia et al., 1978). A circulating factor (Levene et al., 1969) which decreases the ability of the host lymphocytes to be transformed appears to play a part. The immunosuppressive factor may be of bacterial origin,

Address for reprints: Dr S. Graves, Department of Microbiology, Monash University Medical School, Alfred Hospital, Prahran 3181, Australia

Received for publication 8 May 1979 resulting in 'antigenic overload' (Musher et al., 1976), or of host origin-for example, an antibody (Medici, 1972). In either case, its concentration should theoretically rise soon after infection and then fall again as latency is established and the host becomes immune.

To investigate whether or not this occurs, samples of serum were taken at monthly intervals from infected rabbits until they became immune. These sera were used to immunise passively normal rabbits which were then challenged with $T$. pallidum; the course of infection was followed to see whether or not serum 'immunosuppressive' or serum 'protective' factors had been transferred.

The $T$. pallidum strain used in the study was isolated in 1977 from an anal chancre of a male homosexual in Melbourne, Australia. Since most recent work in the field of syphilis immunology has been carried out using the Nichols strain (Nichols, 1914), isolated many decades previously, we investigated the protective properties of immune rabbit serum raised against this current $T$. pallidum strain and compared it with information already available about immune serum against the Nichols strain. 


\section{Materials and methods}

ISOLATION OF TREPONEMA PALLIDUM

(MELBOURNE 1 STRAIN)

This strain of $T$. pallidum was isolated in February 1977 from a small anal lesion (positive by darkfield microscopy) of a male homosexual by inoculation of the exudate into a rabbit testis. After $4 \frac{1}{2}$ months the rabbit developed antitreponemal antibodies and by six months treponemes were observed by darkfield microscopy of an aspirate from the orchitic testis. The rabbit was killed and an eluate from a minced testis transferred to another rabbit by intratesticular inoculation and the strain maintained in this manner.

HARVEST OF T. PALLIDUM

After intratesticular inoculation of approximately $5 \times 10^{7} T$. pallidum per testis orchitis developed in about two weeks. Orchidectomy with an aseptic technique was performed on the rabbit immediately after it had been killed by intravenous injection of $4 \mathrm{ml}$ sodium pentobarbitone $(200 \mathrm{mg} / \mathrm{ml})$. The testes were minced in sterile anaerobic $T$. pallidum maintenance medium (Graves et al., 1975) and the eluted $T$. pallidum adjusted to the required concentration. Counts were made in a bacterial counting chamber under darkfield microscopy. The eluted $T$. pallidum usually had a concentration of about $10^{7} / \mathrm{ml}$. Dilutions were carried out under a stream of sterile, oxygen-free nitrogen.

EXPERIMENTAL INFECTION WITH $T$. PALLIDUM Each of seven adult rabbits was inoculated intradermally into its shaved back with $3 \times 10^{6} T$. pallidum. These rabbits were bled at monthly intervals to provide sera. Rabbits were housed at $18^{\circ} \mathrm{C}$ and fed antibiotic-free feed and water in unrestricted quantities.

\section{SEROLOGICAL MONITORING}

At monthly intervals antitreponemal antibody tests were performed on the individual sera and the pooled serum. Rapid plasma reagin (RPR) (Hynson, Wescott and Dunning, Baltimore) and Treponema pallidum haemagglutination (TPHA) tests (Fujizaki Pharmaceutical Co. Ltd., Shinjuku-ku, Tokyo) were performed according to the manufacturers' direction.

TRANSFER OF SERA

Sera taken each month from the infected rabbits were pooled and stored frozen until the final (sixmonth) samples were obtained. Each of the monthly pools were then sterilised by filtration through a $0.45 \mu \mathrm{m}$ Millipore filter. Twenty-one adult male rabbits were selected as recipients of the serum and divided into seven groups of three rabbits: group 1 received no serum; group 2, normal serum; group 3, one-month serum; group 4, two-month serum; group 5 (one rabbit died during administration of the serum), three-month serum; group 6, four-month serum; and group 7, six-month serum. Each rabbit received a total of $50 \mathrm{ml}$ serum, given in five intravenous doses of $10 \mathrm{ml}$ at nine, seven, five, and two days and two hours before challenge.

\section{T. PALLIDUM CHALLENGE OF RECIPIENT \\ RABBITS}

Each rabbit had its back shaved and marked into a $10-\mathrm{cm} \times 10-\mathrm{cm}$ grid of 16 squares. The challenge doses of $T$. pallidum used were $10^{4}, 10^{3}, 10^{2}$, and 10 , all given intradermally (i.d.) in quadruplicate. Rabbits were kept shaved and were examined daily for the appearance of syphilitic lesions at the inoculation sites. The first sign of a definite induration at the site of inoculation was taken as the end of the latent period for that particular inoculum. The diameter of the zone of induration of each syphilitic lesior was measured 28 days after challenge. Rabbits were examined daily for 34 days after challenge and again on days 42 and 68 . No new lesions appeared after day 32 . During the observation period rabbits were housed at $18^{\circ} \mathrm{C}$ as before.

\section{TEST OF IMMUNE STATUS OF DONOR RABBITS}

A few days after the six-month serum collection from the seven infected rabbits, each of these rabbits was challenged intradermally with $10^{6} T$. pallidum at a shaved site on the back. None of these inoculation sites developed into syphilitic lesions, indicating that rabbits donating serum six months after infection were immune to rechallenge-that is, the serum taken from the six-month donor rabbits was in fact from immune rabbits.

\section{Results}

The donor rabbits, infected with $3 \times 10^{6} T$. pallidum i.d., developed positive TPHA and RPR titres by one month after infection, with the exception of one rabbit which gave a negative result to the RPR test. By two months, the TPHA titres had reached a maximum (Table 1 ). However the only observed effect of the one-month and two-month sera on the recipient rabbits (after transfer of the serum and challenge with $T$. pallidum) was to produce apparently smaller lesions compared with normal rabbit serum and then only after a $10^{4}$ challenge-dose (data not presented). Anti- $T$. pallidum antibodies present within two months of infection appeared to have very little host-protective ability. 
Table 1 Syphilis serology on pooled rabbit sera taken up to six months after infection with $T$. pallidum $\left(3 \times 10^{6}\right.$ i.d., Melbourne 1 strain)

\begin{tabular}{lll}
\hline $\begin{array}{l}\text { Time after } \\
T . \text { pallidum }\end{array}$ & \multicolumn{2}{l}{ Test results } \\
\cline { 2 - 3 } infection (months) & $R P R$ & $T P H A$ titre \\
\hline 0 (preinfection) & - & $<1 / 80$ \\
1 & $+^{*}$ & $1 / 1280 \ddagger$ \\
2 & $+^{*}$ & $1 / 5120 \S$ \\
3 & $+\dagger$ & $1 / 5120 \S$ \\
4 & $+\dagger$ & $1 / 5120 \S$ \\
6 & $+\dagger$ & $1 / 5120 \S$ \\
\hline
\end{tabular}

+ Positive - negative

*One of seven rabbits still negative

+ All seven rabbits positive

\# Range of titres from individual rabbits, $1 / 320-1 / 5120$

$\$$ Range of titres from individual rabbits, $1 / 1280-1 / 5120$

Serum taken three months after infection retarded the development of lesions after challenge with $10^{4} T$. pallidum (Table 3 ) and reduced the number of inoculation sites that developed into syphilitic lesions after challenge with $10 T$. pallidum (Table 2). It therefore had some protective effect.

Serum taken four months after infection reduced the size of the syphilitic lesions, retarded their development (increased latent period) after challenge with $10^{4} T$. pallidum (Table 3 ), and reduced the number of inoculation sites that developed into syphilitic lesions after challenge with $10 T$. pallidum (Table 2). This serum also had some protective ability.

Serum taken six months after infection significantly reduced the number of inoculation sites that developed into syphilitic lesions after challenge with $10 \mathrm{~T}$. pallidum (Table 2) and also retarded the development of lesions after challenge with $10^{4} T$. pallidum (Table 3). It was the most protective of the sera tested. However none of the sera had any significant effect on $10^{3}$ and $10^{2} T$. pallidum challenge doses.

In general, none of the transferred sera was markedly successful in modifying the course of the $T$. pallidum infection. Depending on the criteria of protection used, different sera had varying (but minimal) protective ability. On the basis of the reduction in the number of inoculation sites developing into syphilitic lesions, the immune sera taken at three and six months were equally protective, while on the basis of the retardation of the development of syphilitic lesions, the immune sera taken at four and six months were equally protective.

Table 2 Number of $T$. pallidum lesions (numerator) in serum-treated rabbits as a fraction of total intradermal inoculation sites (denominator) for four different $T$. pallidum (Melb. I) inoculation doses after passive transfer of syphilitic rabbit sera

\begin{tabular}{|c|c|c|c|c|}
\hline \multirow{3}{*}{$\begin{array}{l}\text { Passive transfer to recipient rabbits (in } \\
\text { months after } T \text {. pallidum infection) }\end{array}$} & T. pallidum lesions & \multirow{2}{*}{\multicolumn{3}{|c|}{ for four different $T$. pallidum inocula }} \\
\hline & Inoculation sites & & & \\
\hline & 104 & 103 & 102 & 10 \\
\hline $\begin{array}{l}\text { None } \\
\text { Normal rabbit serum } \\
1 \\
2 \\
3 \\
4 \\
6\end{array}$ & $\begin{array}{l}12 / 12 \\
12 / 12 \\
12 / 12 \\
12 / 12 \\
8 / 8 \\
12 / 12 \\
12 / 12\end{array}$ & $\begin{array}{l}12 / 12 \\
12 / 12 \\
12 / 12 \\
12 / 12 \\
8 / 8 \\
12 / 12 \\
12 / 12\end{array}$ & $\begin{array}{l}12 / 12 \\
12 / 12 \\
12 / 12 \\
12 / 12 \\
8 / 8 \\
12 / 12 \\
11 / 12\end{array}$ & $\begin{array}{l}12 / 12 \\
12 / 12 \\
12 / 12 \\
12 / 12 \\
4 / 8 \\
9 / 12 \\
7 / 12\end{array}$ \\
\hline
\end{tabular}

Table 3 Latent period (days) for the development of syphilitic lesions in recipient rabbits after intradermal infection with graded doses of $T$. pallidum

\begin{tabular}{|c|c|c|c|c|c|c|c|c|}
\hline \multirow{3}{*}{$\begin{array}{l}\text { Passive transfer to recipient rabbits } \\
\text { (in months after } T \text {. pallidum infection } \\
\text { of donor rabbits) }\end{array}$} & \multicolumn{8}{|c|}{$\begin{array}{l}\text { Latent period (days) after four different } \\
\text { Treponema pallidum challenge doses }\end{array}$} \\
\hline & \multicolumn{2}{|l|}{104} & \multicolumn{2}{|l|}{103} & \multicolumn{2}{|l|}{102} & \multicolumn{2}{|l|}{10} \\
\hline & Mean & $S D$ & Mean & $S D$ & Mean & $S D$ & Mean & $S D$ \\
\hline $\begin{array}{l}\text { None } \\
\text { Normal rabbit serum } \\
1 \\
2 \\
3 \\
4 \\
6\end{array}$ & $\begin{array}{l}10 \cdot 2 \\
12 \cdot 8 \\
10 \cdot 8 \\
14 \cdot 2 \\
17 \cdot 4 \\
16 \cdot 2 \\
15 \cdot 7\end{array}$ & $\begin{array}{l}2 \cdot 1 \\
1 \cdot 9 \\
1 \cdot 5 \\
1 \cdot 8 \\
3 \cdot 4^{*} \\
1 \cdot 2 \dagger \\
0.9+\end{array}$ & $\begin{array}{l}11 \cdot 7 \\
17 \cdot 0 \\
13 \cdot 0 \\
17 \cdot 2 \\
18 \cdot 5 \\
17 \cdot 8 \\
17 \cdot 7\end{array}$ & $\begin{array}{l}0 \cdot 5 \\
2 \cdot 3 \\
1 \cdot 5 \\
2 \cdot 1 \\
2 \cdot 4 \\
1 \cdot 8 \\
1 \cdot 6\end{array}$ & $\begin{array}{l}16 \cdot 6 \\
20 \cdot 4 \\
16 \cdot 0 \\
20 \cdot 3 \\
22 \cdot 2 \\
20 \cdot 1 \\
19 \cdot 9\end{array}$ & $\begin{array}{l}2 \cdot 0 \\
2 \cdot 6 \\
1 \cdot 3 \\
1 \cdot 7 \\
3 \cdot 5 \\
2 \cdot 0 \\
2 \cdot 7\end{array}$ & $\begin{array}{l}21 \cdot 0 \\
22 \cdot 9 \\
21 \cdot 1 \\
24 \cdot 2 \\
24 \cdot 5 \\
22 \cdot 9 \\
24 \cdot 7\end{array}$ & $\begin{array}{l}2 \cdot 7 \\
3 \cdot 2 \\
1 \cdot 9 \\
3 \cdot 2 \\
1 \cdot 7 \\
1 \cdot 8 \\
3 \cdot 6\end{array}$ \\
\hline
\end{tabular}

* Significant difference $(\mathrm{P}<0.005)$ by Student's $t$ test when compared to normal serum transfer + Significant difference $(P<0 \cdot 001)$ by Student's $t$ test when compared to normal serum transfer $\mathrm{SD}=$ Standard deviation 


\section{Discussion}

Using the Nichols strain of $T$. pallidum, a number of investigators have already shown that the transfer of immune rabbit serum to normal rabbits, and their subsequent challenge, does not completely protect the recipient rabbits (Perine et al., 1973; Sepetjian et al., 1973; Turner et al., 1973; Graves and Johnson, 1975; Bishop and Miller, 1976a; Weiser et al., 1976). Depending on the dose of immune serum given and its time of administration in relation to the challenge with $T$. pallidum, the development of syphilitic lesions may be retarded (that is, they have longer latent periods), with atypical morphology (smaller and less indurated), and regress more quickly, possibly without ulceration. With very low challenge doses of $T$. pallidum, lesions may even be completely prevented.

In our experiment we transferred five lots of $10-\mathrm{ml}$ volumes of serum per rabbit over a nine-day period, the last dose being two hours before challenge with $T$. pallidum. The rationale for this procedure was to ensure a high level of transferred serum proteins throughout the tissues of the recipient rabbits at the time of first exposure to introduced $T$. pallidum. Sequential addition of immune serum to normal rabbits has produced rising antibody titres (Sepetjian et al., 1973).

Where a protective effect was observed immune serum may either kill some of the introduced challenge $T$. pallidum or (more likely) be bacteriostatic. Thus, as the passively introduced antibodies decay the treponemes start to grow and establish a (modified) infection. Antibody and complement are apparently not bactericidal in vivo unlike in vitro (TPI test, Nelson and Mayer, 1949). This may be because in vitro the $T$. pallidum cannot grow and maintain its structural integrity. A similar phenomenon has been reported with Haemophilus influenzae type $b$, which is resistant to antibodies in a medium supporting growth but is lysed by antibodies in a medium that does not support growth (Newman et al., 1973).

It is now well recognised that immunity to $T$. pallidum is slow to develop in both humans (Chesney, 1927) and rabbits (Eberson, 1921; Turner and Hollander, 1957). Recently Bishop and Miller (1976b) detected some immunity in rabbits as early as 11 days after infection, but not until three months were all their rabbits completely resistant to challenge.

In our experiments the first two serum samples taken after rabbit infection with $T$. pallidum (at one and two months) apparently had some protective ability as shown by a statistically significant reduction in the size of the syphilitic lesions produced by a challenge with $10^{4} T$. pallidum. However no similar protection was found after challenge with $10^{3}$, $10^{2}$, or $10 T$. pallidum making this protective effect of doubtful significance. The sera taken at three, four, and six months after infection not only retarded the appearance of the syphilitic lesions after challenge with $10^{4} T$. pallidum but also reduced the number of inoculation sites developing into lesions after challenge with $10 \mathrm{~T}$. pallidum. In addition the serum taken at four months also reduced the size of the lesion after challenge with $10^{4} T$. pallidum. These observations indicate that protective factors were gradually being produced by the $T$. pallidum-infected rabbits. There was no evidence that any serum contained an immunosuppressive factor, although if it were present at low levels it may have been masked by the protective factors which were probably antibodies. In general, the longer the period of infection in the rabbit the greater the degree of passive immunity conferred by serum from that rabbit, but immunity was never complete.

Possibly, if serum had been taken less than one month after infection, the presence of immunosuppressive factors in the serum could have been inferred should there have been more rapid growth of the challenge $T$. pallidum in the serum-recipient rabbits than in the control rabbits. Furthermore, the factor or factors responsible for early immunosuppression in syphilis may possibly be cell-bound.

Normal rabbit serum gave some level of protection against a challenge with $T$. pallidum (Table 3 ), and consequently all comparisons were made between transfer with immune and normal serum rather than with no serum. The presence of rabbit protein on the surface of the introduced $T$. pallidum (Logan 1974) may have resulted in a cross-reaction to allotypic differences in these proteins owing to the immunisation of the recipient rabbit with the transferred immune rabbit serum proteins nine days before challenge.

In this study a new, recently isolated strain of $T$. pallidum (Melbourne 1) was used. All recent experimental work in syphilis immunology has involved the use of the Nichols strain, which may be atypical. Nichols (1914) himself thought this was so. Other workers have also suggested that there is serological heterogeneity among $T$. pallidum (Eberson, 1921; Chesney, 1927; Turner and Hollander, 1957). Our observations on the Melbourne 1 strain suggest that the basis of immunity is only partially humoral and in this respect it does not differ from the Nichols strain.

In hamsters the closely related bacterium, Treponema pertenue, can be prevented from producing cutaneous lesions by the passive transfer of immune serum (Schell et al., 1978) but, as in 
syphilis, immune serum does not completely protect the host from infection.

The authors wish to thank Mr Ian McLean for excellent technical assistance. This work was supported by the National Health and Medical Research Council (Australia), the Utah Foundation, the Potter Foundation, the Danks Trust, the estate of the late George Adams, and Monash University, from whom financial assistance is gratefully acknowledged.

\section{References}

Bishop, N. and Miller, J. (1976a). Humoral immunity in experimental syphilis. I. The demonstration of resistance conferred by passive immunization. Journal of Immunology, 117, 191-196.

Bishop, N. and Miller, J. (1976b). Humoral immunity in experimental syphilis. II. The relationship of neutralizing factors in immune serum to acquired resistance. Journal of Immunology, 117, 197-207.

Chesney, A. (1927). Immunity in syphilis. Medicine Monographs, volume 12. Williams and Wilkins Co: Baltimore.

Eberson, F. (1921). Immunity studies in experimental syphilis. Archives of Dermatology and Syphilology, 4, 490-511.

Graves, S. and Johnson, R. (1975). Effect of pretreatment with Mycobacterium bovis (strain BCG) and immune syphilitic serum on rabbit resistance to Treponema pallidum. Infection and Immunity, 12, 1029-1036.

Graves, S., Sandok, P., Jenkins, H., and Johnson, R. (1975). Retention of motility and virulence of Treponema pallidum (Nichols strain) in vitro. Infection and Immunity, 12, 1116-1120.

Levene, G., Turk, J., Wright, D., and Grimble, A. (1969). Reduced lymphocyte transformation due to a plasma factor in patients with active syphilis. Lancet, 2, 246-247.
Logan, L. (1974). Rabbit globulin and antiglobulin factors associated with Treponema pallidum grown in rabbits. British Journal of Venereal Diseases, 50, 421-427.

Magnuson, H., Thomas, E., Olansky, S., Kaplan, B., DeMello, L., and Cutler, J. (1956). Inoculation syphilis in human volunteers. Medicine, 35, 38-82.

Medici, M. (1972). The immunoprotective niche-a new pathogenic mechanism for syphilis, the systemic mycoses and other infectioius diseases. Journal of Theoretical Biology, 36, 617-625.

Musher, D., Schell, R., and Knox, J. (1976). The immunology of syphilis. International Journal of Dermatology, 15, 566-576.

Nelson, R. and Mayer, M. (1949). Immobilization of Treponema pallidum in vitro by antibody produced in syphilitic infection. Journal of Experimental Medicine, 89, 369-393.

Newman, S., Waldo, B., and Johnson, R. (1973). Separation of serum bactericidal and opsonizing activities for Haemophilus influenzae type b. Infection and Immunity, 8, 488-490.

Nichols, H. (1914). Observations on a strain of Spirochaeta pallida isolated from the nervous system. Journal of Experimental Medicine, 19, 362-372.

Pavia, C., Folds, J., and Baseman, J. (1978). Cell-mediated immunity during syphilis. British Journal of Venereal Diseases, 54, 144-150.

Perine, P., Weiser, R., and Klebanoff, S. (1973). Immunity to syphilis. I. Passive transfer in rabbits with hyperimmune serum. Infection and Immunity, 8, 787-790.

Schell, R., LeFrock, J., and Babu, J. (1978). Passive transfer of resistance to frambesial infection in hamsters. Infection and Immunity, 21, 430-435.

Sepetjian, M., Salussola, D., and Thivolet, J. (1973). Attempt to protect rabbits against experimental syphilis by passive immunization. British Journal of Venereal Diseases, 49, 335-337.

Turner, T., Hardy, P., Newman, B., and Nell, E. (1973). Effects of passive immunization on experimental syphilis in the rabbit. Johns Hopkins Medical Journal, 133, 241-251.

Turner, T. and Hollander, D. (1957). Biology of the treponematoses. Monograph Series No. 35 World Health Organisation: Geneva.

Weiser, R., Erickson, D., Perine, P., and Pearsall, N. (1976). Immunity in syphilis: Passive transfer in rabbits using serial doses of immune serum. Infection and Immunity, 13, 1402-1407. 